\title{
Retrospective Analysis of Therapeutic Drug Monitoring Data for Treatment of Bipolar Disorder with Lamotrigine
}

Authors

Affiliation

\section{S. Unholzer, E. Haen}

Klinische Pharmakologie am Lehrstuhl mit Poliklinik für Psychiatrie und Psychotherapie und am Lehrstuhl für Pharmakologie und Toxikologie der Universität Regensburg/Germany
Key words

- lamotrigine

- bipolar disorder

- mood stabilizer

- TDM

therapeutic reference range

\section{Abstract}

$\nabla$

Introduction: Lamotrigine is licensed for treatment of epilepsy and prevention or at least delay of depressive episodes in bipolar disorder. The accepted therapeutic reference range (TRR) of lamotrigine for anticonvulsant treatment is $3000-14000 \mathrm{ng} / \mathrm{ml}$. This TRR is often used for the therapy of bipolar disorders as well. This work presents serious doubts about this approach.

Methods: KONBEST, a large TDM database containing patients' characteristics including diagnoses, doses, comedication and serum concentrations, was analyzed. Out of a total of 3459 lamotrigine samples, 360 patients suffered from bipolar disorder. 82 of them benefitted from therapy with lamotrigine as judged by the

\section{Introduction}

$\nabla$

$\begin{array}{ll}\text { received } & 28.04 .2015 \\ \text { revised } & 14.07 .2015 \\ \text { accepted } & 17.07 .2015\end{array}$

Bibliography

DOI http://dx.doi.org/

10.1055/s-0035-1559635

Published online:

August 7, 2015

Pharmacopsychiatry 2015;

48: 211-214

(C) Georg Thieme Verlag KG

Stuttgart · New York

ISSN 0176-3679

Correspondence

\section{S. Unholzer}

Lehrstuhl für Pharmakologie und Toxikologie der Universität Regensburg

Universitätsstr. 31

D-93053 Regensburg

Germany

Sandra.Unholzer@klinik.uni-

regensburg.de
In Europe, lamotrigine is licensed for 2 indications: in neurology for the treatment of epilepsy and in psychiatry for the prevention or at least delay of depressive episodes in bipolar-I disorders of adults [1]. In clinical trials lamotrigine was not more effective than placebo in the treatment of acute manic or depressive episodes [2]. For anticonvulsant treatment, the accepted TRR of lamotrigine is $3000-14000 \mathrm{ng} / \mathrm{ml}$ [3]. Although TDM is recommended to optimize treatment of bipolar disorders with lamotrigine (recommendation level 2 [3]), thus far there is no particular TRR for that indication. Therefore, this study was designed to check if another TRR has to be established for TDM-guided treatment of bipolar disorder.

\section{Materials and Methods}

$\nabla$

KONBEST, a database continuously filled with TDM data under conditions of daily routine, was analyzed [4]. Besides the clinical reasons for clinical global impression of improvement (CGII) scale. Patients with a score of minimally (3), much (2) or very much improved (1) were considered as responders.

Results: The recommended lamotrigine maintenance dose for bipolar disorder is $200 \mathrm{mg} /$ day; the doses prescribed in our samples ranged from 25 to $450 \mathrm{mg} /$ day. Only 32 concentrations (39.0\%) fitted into the TRR recommended for therapy of epilepsy; 50 (61.0\%) did not reach it, none exceeded it. The lowest concentration was $177 \mathrm{ng} / \mathrm{ml}$, the highest $11871 \mathrm{ng} / \mathrm{ml}$. A mean lamotrigine serum concentration of $3341 \pm 2563 \mathrm{ng} / \mathrm{ml}(\overline{\mathrm{X}} \pm \mathrm{SD})$ was detected in the patients who benefitted.

Discussion: The authors conclude that in bipolar disorder lower lamotrigine serum concentrations lead to therapeutic benefit.

requesting lamotrigine serum concentrations, the lamotrigine dose, its corresponding serum concentration, its relation to the dose-related reference range (DRR) and to the TRR, KONBEST contains the patient's characteristics including gender, age, diagnoses, and comedication. Lamotrigine trough steady-state serum levels were measured by HPLC with UV detection [5].

The retrospective analysis comprised data stored between February 2005 and January 2015. Therapeutic outcome was evaluated by the clinical global impression of improvement (CGI-I) scale ( $1=$ very much improved; 2 =much improved; $3=$ minimally improved; 4=no change; 5=minimally worse; $6=$ much worse; $7=$ very much worse) [6]. CGI scores were rated just after blood was drawn for measurement; rating was thus blind for the lamotrigine concentration detected later in the laboratory. Patients with a score of 3,2 or 1 were considered as responders. The arithmetic mean \pm 1 standard deviation $(\overline{\mathrm{X}} \pm \mathrm{SD})$ of responders' lamotrigine serum concentrations was taken as an indicator for a possible TRR for lamotrigine in the prevention of depressive episodes in bipolar disorder. 
Lamotrigine serum concentrations were plotted against the resulting CGI-I scores and against the prescribed doses. Unless otherwise indicated, population data are given as $\bar{X} \pm 1 S D$. The correlation was statistically validated by linear regression and Pearson correlation. $\mathrm{p}<0.05$ was set as statistically significant.

\section{Results}

$\nabla$

3459 data sets were identified in the KONBEST database with blood specimens quantified for lamotrigine. A diagnosis was submitted with 1471 of the specimens; 360 patients suffered from bipolar disorder (F31, [7]). 82 of them benefitted from therapy with lamotrigine ( $=100 \%$ of responders). 26 patients (31.7\%) were males, 56 (68.3\%) females, aged between 25 and 83 ( $\overline{\mathrm{X}} \pm$ SD: $52 \pm 14$ years, $1 \mathrm{x}$ no information). 34 patients $(41.5 \%)$ smoked, 56 (69.1\%) consumed caffeine. In 171 requests a clinical question was formulated for requesting a lamotrigine serum level. In 39 of these requests $(22.8 \%)$ the clinicians asked whether the lamotrigine concentration would fit into the TRR ( $\bullet$ Fig. 1).

The lamotrigine maintenance dose recommended for bipolar disorder is $200 \mathrm{mg} /$ day; the doses actually prescribed in our sample ranged from 25 to $450 \mathrm{mg} /$ day $(161.8 \pm 82.6 \mathrm{mg}): 44$ patients (53.7\%) were treated with $<200 \mathrm{mg}$ lamotrigine/day, 24 patients (29.3\%) with $200 \mathrm{mg} /$ day, and 12 patients (14.6\%) with $>200 \mathrm{mg} /$ day (2x no information). The lowest concentration was $177 \mathrm{ng} / \mathrm{ml}$, the highest $11871 \mathrm{ng} / \mathrm{ml}(\overline{\mathrm{x}} \pm \mathrm{SD}=3341 \pm 2563 \mathrm{ng} /$ $\mathrm{ml}$, Table 1). 34 concentrations (41.5\%) fitted into DRR, 17 (20.7\%) were above DRR (13 of them with valproate as comedication, 1 with blood draw after tablet-taking, 2 without an explanation, 1 just slightly above), and 29 (35.4\%) below DRR (17 non-compliant patients, 3 with slightly too low concentrations, 3 outside steady state, 1 with drug interactions and 5

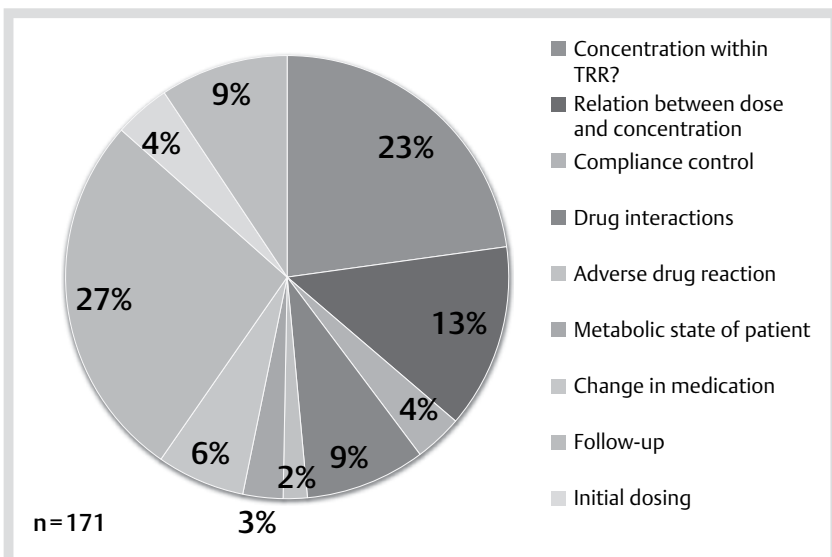

Fig. 1 Reasons for requesting a lamotrigine serum level. (Color figure available online only).

Table 1 Prescribed doses and measured serum concentrations of lamotrigine.

\begin{tabular}{|lcc|}
\hline & Maintenance dose [mg] & Concentration [ng/ml] \\
\hline Highest value & 450 & 11871 \\
\hline Lowest value & 25 & 177 \\
\hline MW & 161.8 & 3341.1 \\
\hline SD & 82.6 & 2563.4 \\
\hline MW+SD & 244.4 & 5904.5 \\
\hline MW-SD & 79.2 & 777.7 \\
\hline
\end{tabular}

without obvious reasons). Only 32 of 82 lamotrigine concentrations (39.0\%) fitted into the TRR recommended for therapy of epilepsy, 50 concentrations $(61.0 \%)$ did not reach it, none exceeded it ( $\odot$ Table 2, $\odot$ Fig. 2 ).

57 patients with a CGI-I score of 3 (minimally improved) had a mean serum concentration of $3118 \pm 2522 \mathrm{ng} / \mathrm{ml}$ with a mean dose of $154.4 \pm 82.7 \mathrm{mg} /$ day. 21 patients with a CGI-I score of 2 had mean serum concentrations of $4092 \pm 2608 \mathrm{ng} / \mathrm{ml}$ with a mean dose of $173.8 \pm 75.0 \mathrm{mg} /$ day. Only 4 samples were available from patients with a CGI-I score of 1 . Their mean serum concentration was $2578 \pm 2033 \mathrm{ng} / \mathrm{ml}$, the mean prescribed dose was $200.0 \pm 100.0 \mathrm{mg} /$ day ( $\bullet$ Fig. 3). No positive linear correlation could be statistically validated between lamotrigine serum concentrations and CGI-I scores $(\mathrm{p}=-0.080)$. Correlating just the lamotrigine concentrations to CGI-I scores 2 and 3, a higher serum concentration of lamotrigine seems to lead to therapeutically better effects. But this difference could not be statistically validated. The arithmetic mean of lamotrigine serum concentrations of all 82 responders was calculated as $3341 \pm 2563 \mathrm{ng} / \mathrm{ml}$. Non-responders (CGI-I score 4-7) had mean lamotrigine serum levels of $3483.23 \pm 2556.58 \mathrm{ng} / \mathrm{ml}$ (॰ Fig. 4).

\section{Discussion}

$\nabla$

There is no doubt that it is the concentration of a drug, not its dose, that is responsible for its efficacy. Therefore quantifying the concentration of a drug in an individual patient should always be the basis of drug therapy ( = therapeutic drug monitoring, TDM). High-quality equipment and analytical methods, valid reference ranges (DRR [8] and TRR) as well as a clinical pharmacological comment interpreting the measured value [9] are needed to optimize pharmacotherapy with TDM $[3,10]$. KONBEST is a web-based laboratory information system especially designed to allow handling and commenting of TDM data; it is connected to a database that stores all necessary data on a strictly anonymous basis $[4,10]$.

Unfortunately there are no clinical studies yet particularly designed to validate a TRR for the use of lamotrigine in bipolar disorder. The only TRR available for TDM is the one established for the prevention of epileptic seizures. Unless otherwise proven the same concentrations do not have to be necessarily effective for the prevention of depressive episodes in bipolar disorders, too. In quantifying lamotrigine in patients' samples within the daily routine, it has been our impression that many concentrations were below the neurologic TRR. In psychiatry, lower serum concentrations than in antiepileptic therapy seemed to have a therapeutic effect. We found 3 publications in the literature that addressed the topic as well. Katayama et al. determined lamotrigine concentrations under the lamotrigine doses recom-

Table 2 Values for dose-related and therapeutic reference range.

\begin{tabular}{|c|c|c|}
\hline & $\begin{array}{l}\text { Dose-related reference } \\
\text { range (DRR) }\end{array}$ & $\begin{array}{l}\text { Therapeutic reference } \\
\text { range (TRR) }\end{array}$ \\
\hline Fitting & 34 & 32 \\
\hline$\%(n=82)$ & 41.5 & 39.0 \\
\hline Above & 17 & 0 \\
\hline$\%(n=82)$ & 20.7 & 0.0 \\
\hline Below & 29 & 50 \\
\hline$\%(n=82)$ & 35.4 & 61.0 \\
\hline Not reported & 2 & - \\
\hline$\%(n=82)$ & 2.3 & - \\
\hline
\end{tabular}




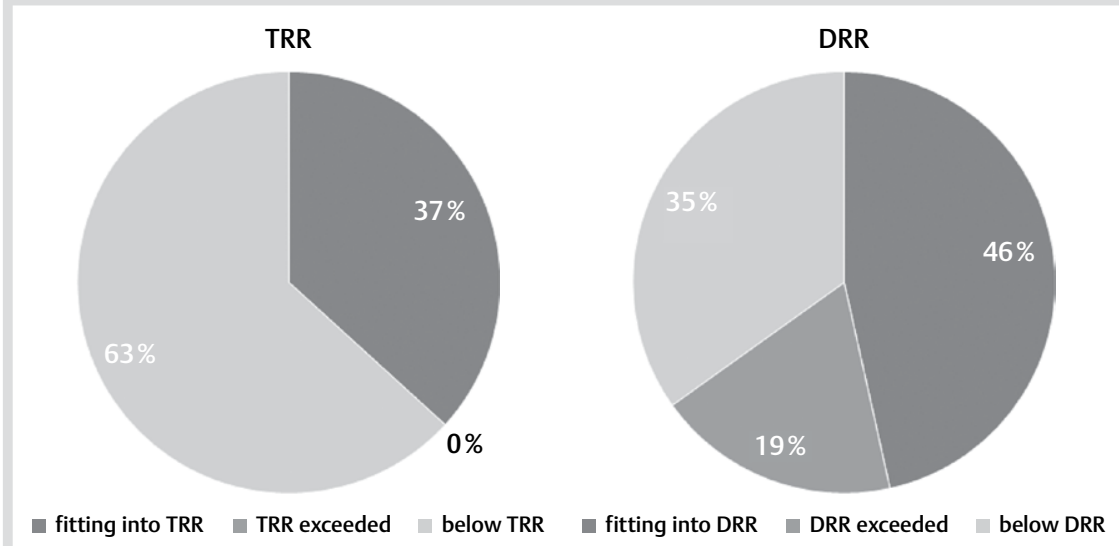

Fig. 2 Dose-related reference range (DRR) and therapeutic reference range (TRR). (Color figure available online only).

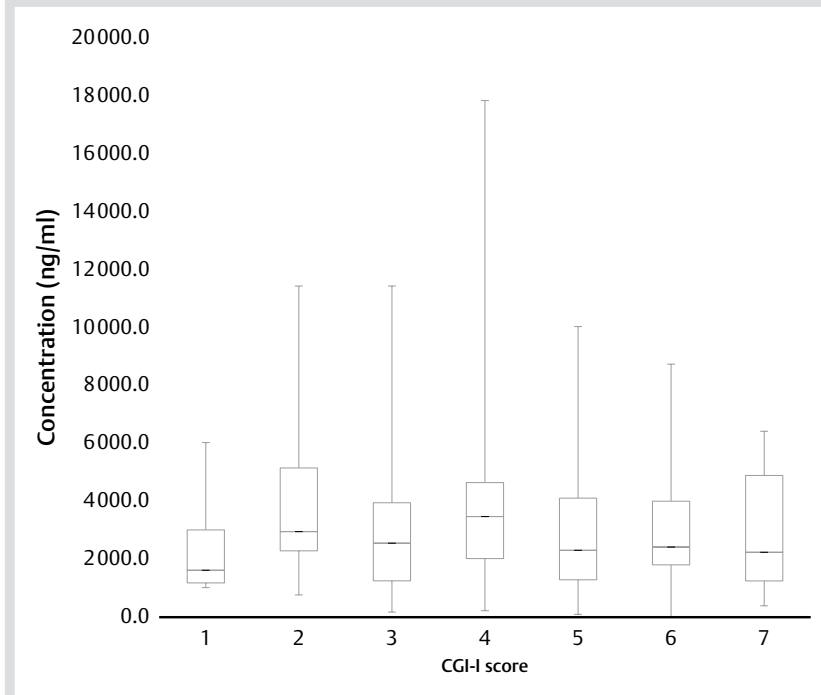

Fig. 3 CGI-I scores: box plot. (Color figure available online only).

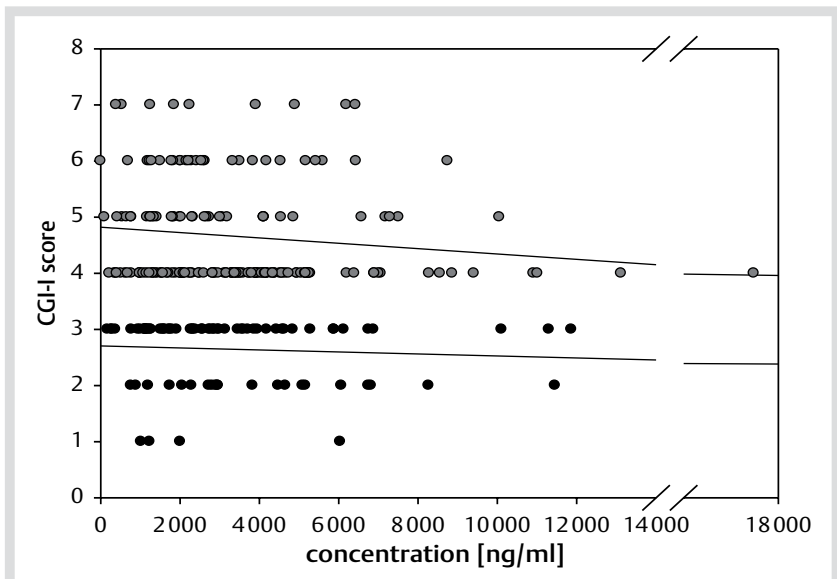

Fig. 4 Serum concentrations and resulting CGI scores. (Color figure available online only).

mended for bipolar disorder in 25 Asian patients suffering from various kinds of mood disorders (18 BP-II patients, 1 BP-I patient, 5 major depressive patients) and suggested a therapeutic reference range of $5000-11000 \mathrm{ng} / \mathrm{ml}$ [11]. Lamotrigine clearance is $28.7 \%$ lower in the Asian population [12]. This may explain why Katayama et al. detected such high serum concentrations under the dosage that is uniquely recommended for bipolar disorders all over the world. The same holds true for the study by Kagawa et al., who studied 34 patients suffering from various kinds of treatment-resistant affective disorders; 12 patients were not treated for a bipolar disorder but for a unipolar depressive episode [13]. Kagawa et al. even suggested a lamotrigine concentration above $12700 \mathrm{nmol} / \mathrm{L}$, which in our opinion was necessary because the symptomatology of their patients had already proven to be treatment-resistant. This study population is not the population lamotrigine is licensed for in psychiatry.

A European study by Grunze et al. had earlier suggested that lower lamotrigine concentrations were effective in bipolar disorders [14]. These authors had observed 14 rapid cycling patients who were treated either with lamotrigine or lithium in monotherapy for one year. 3 patients did not have any mood episode under lamotrigine therapy. All of them had serum levels above $5000 \mathrm{ng} / \mathrm{ml}$, while partial or non-responders had serum levels between 2400 and $4900 \mathrm{ng} / \mathrm{ml}$.

This prompted us to retrospectively analyze the data in our KONBEST database, in which all data obtained during our daily routine of quantifying drug serum concentrations were stored anonymously since 2006 [4]. An advantage of this approach is the large amount of data (3459 samples) we could include in this analysis compared to the earlier publications. It is a pity, however, the indication was given in only $43 \%$ of the lamotrigine requests, demonstrating how little attention is paid under routine conditions to properly filling in request forms. Nevertheless, 82 data sets remained for our analysis, still 2-4 times the number of cases reported in the earlier publications. Moreover, we could restrict the diagnosis to ICD-10 F31 (bipolar affective disorder), whereas Grunze et al. studied only rapid cycling patients, Katayama et al. patients suffering from all kinds of affective disorders (among them many unipolar depressed patients), and Kagawa et al. treatment-resistant affective disorders.

The lamotrigine maintenance dose recommended for bipolar disorder is $200 \mathrm{mg} /$ day; in our samples lamotrigine was actually prescribed very carefully, with $>50 \%$ of the patients prescribed less than the recommended dosage. Therefore it is not surprising that most of the serum concentrations detected were below the TRR. The data presented here demonstrate that just roughly half of the patients were within the expected DRR. The other concentrations deviated from the expected DRR. Most of the concentrations that did not reach the DRR were diagnosed in the clinical pharmacological comment as compliance problems; most of the concentrations that exceeded the DRR exceeded it because of drug-drug interactions, which means that some of the patients 
may have reached the neurologic TRR only because of a drugdrug interaction inhibiting the metabolizing enzyme. Remarkable in this regard are the patients under comedication with valproate. This drug-drug interaction is well known. Lamotrigine is mainly metabolized by conjugation with glucuronic acid and not by the cytochrome- $\mathrm{P}_{450}$-isoenzyme (CYP) system in the liver. The major metabolite is an inactive 2-N-glucuronide conjugate [15]. Valproate blocks the glucuronisation of lamotrigine thereby increasing lamotrigine blood concentration. It is generally recommended to avoid this drug-drug interaction (contraindication). In our opinion, the dosage of lamotrigine must instead be properly adapted, i.e., TDM-guided. As little as $25 \mathrm{mg} /$ day may suffice to reach the TRR as has been shown earlier in a case report [16]. Kagawa et al. lowered their lamotrigine dosage in combination with valproate just by $25 \%$ [13].

In our study the arithmetic mean of lamotrigine serum concentrations of all 82 responders was calculated as $3341 \pm 2563 \mathrm{ng} / \mathrm{ml}$. This implies that lower lamotrigine serum concentrations may suffice for the treatment of bipolar disorder than currently recommended [3]. Non-responders (CGI-I scores 4-7) had mean lamotrigine serum levels of $3483.23 \pm 2556.58 \mathrm{ng} / \mathrm{ml}$. The difference between the groups was not statistically significant. But our data show clinical reality: some of the non-responders might have benefitted from therapy with lamotrigine if the dose had been properly elevated. On the other hand, there are also non-responders with quite high lamotrigine levels. We believe that their disease simply did not respond to lamotrigine; these patients belong to the population studied by Kagawa et al. [13]. We decided not to split our responders with different CGI-I scores into separate groups because we did not find significant differences between them.

The low number of 4 patients with the CGI-I score 1 is due to our patient selection in a retrospective study. Physicians today still decide to draw blood from a patient for quantification of a drug concentration if the therapy does not proceed as expected; usually no blood is drawn from a patient that improves. This, however, is the most important group of patients if a valid TRR is to be established to prevent depressive episodes in bipolar disorder. This is a retrospective study. Retrospective studies always have more or less significant drawbacks. Compared to the small older studies, it is an advantage that we were able to clearly restrict the diagnosis of our patients to just bipolar patients (F31). The clinical improvement of our patients was judged by CGI-I scores, which is a very general and subjective measure of a patient's clinical state; therefore we do not know which symptom in each patient actually improved. In a prospective study the prevention of depressive episodes should be the primary study endpoint. Nevertheless, our data support the hypothesis that much lower lamotrigine concentrations suffice to treat patients suffering from bipolar disorder and responding to lamotrigine than the TRR currently accepted in neurology suggests. We support the proposal of Grunze et al. and of Katayama et al. We agree that the lamotrigine concentration of $14000 \mathrm{ng} / \mathrm{ml}$ suggested to treat epilepsy does not have to be reached in bipolar disorder. We hardly found such high serum concentrations in our samples. There is no doubt that the results and consideration of this study have to be confirmed in a well-designed prospective clinical trial. Our study is just a pilot study to prepare for such a study. Based on our findings such a study should

- strictly focus on the licensed indication, i.e., the prevention of depressive episodes in bipolar disorder;

- exclude patients with treatment-resistant bipolar disorders,
- evaluate the effectiveness of lamotrigine by a validated instrument such as the Montgomery- Åsberg Depression Rating Scale (MADRS), and

- increase the lamotrigine dosage slowly and with TDM guidance into the range of $3300 \pm 2500 \mathrm{ng} / \mathrm{ml}$.

Keeping in mind that lamotrigine is no longer a patented substance, we are not very confident that such a study will be conducted in the near future. Such studies are actually best included in the license study program. Unfortunately, determination of drug concentrations is not yet obligatory. We ask the drug authorities to include quantification of the drug concentration into the license studies to obtain information on individual effects instead of correlating just the dose to its clinical efficacy in a population-based approach.

\section{Conflict of Interest}

$\nabla$

S. Unholzer has nothing to disclose. Dr. Haen reports personal fees from Pfizer Deutschland GmbH, personal fees from Servier Deutschland $\mathrm{GmbH}$, personal fees from Novartis Pharma $\mathrm{GmbH}$, personal fees from Johnson \& Johnson $\mathrm{GmbH}$, outside the submitted work.

\section{References}

1 GlaxoSmithKline GmbH \& Co. KG München/Germany. Lamictal ${ }^{\circledR}$ - Summary of product characteristics. 2014

2 Calabrese JR, Huffman RF, White RL et al. Lamotrigine in the acute treatment of bipolar depression: results of five double-blind, placebocontrolled clinical trials. Bipolar Disorders 2008; 10: 323-333

3 Hiemke C, Baumann P, Bergemann $N$ et al. AGNP consensus guidelines for therapeutic drug monitoring in psychiatry: update 2011. Pharmacopsychiatry $2011 ; 44: 195-235$

4 Köstlbacher A, Haen E. Konbest - A web-based laboratory information management system (LIMS) for TDM laboratories. Pharmacopsychiatry 2008; 41: 212

5 Greiner C, Haen E. Development of a simple column-switching highperformance liquid chromatography (HPLC) method for rapid and simultaneous routine serum monitoring of lamotrigine, oxcarbazepine and 10-monohydroxycarbazepine (MHD). J Chromatogr B Analyt Technol Biomed Life Sci 2007; 854: 338-344

6 Guy W, edited by Rush AJ. Clinical Global Impressions Scale (CGI). Handbook of Psychiatric Measures. Washington, DC: American Psychiatric Association; 2000: 100-102

7 World Health Organization (WHO). The ICD-10 classification of mental and behavioural disorders: clinical descriptions and diagnostic guidelines. World Health Organization; 1992: 50-51

8 Haen E, Greiner C, Bader W et al. Wirkstoffkonzentrationsbestimmungen zur Therapieleitung - Ergänzung therapeutischer Referenzbereiche durch dosisbezogene Referenzbereiche (Engl. abstract: Expanding therapeutic reference ranges using dose-related reference ranges). Der Nervenarzt 2008; 79: 558-566

9 Haen E. Der TDM-Befund (Engl. abstract: The TDM Report). Psychopharmakotherapie 2012; 19: 129-134

10 Haen E. Therapeutic drug monitoring in pharmacovigilance and pharmacotherapy safety. Pharmacopsychiatry 2011; 44: 254-258

11 Katayama Y, Terao T, Kamei Ket al. Therapeutic window of lamotrigine for mood disorders: a naturalistic retrospective study. Pharmacopsychiatry 2014; 47: 111-114

12 Hussein Z, Posner J. Population pharmacokinetics of lamotrigine monotherapy in patients with epilepsy: retrospective analysis of routine monitoring data. Br J Clin Pharmacol 1997; 43: 457-465

13 Kagawa S, Mihara K, Nakamura A et al. Relationship between plasma concentrations of lamotrigine and its early therapeutic effect of lamotrigine augmentation therapy in treatment-resistant depressive disorder. Ther Drug Monit 2014; 36: 730-733

14 Walden J, Schaerer L, Schloesser S, Grunze H. An open longitudinal study of patients with bipolar rapid cycling treated with lithium or lamotrigine for mood stabilization. Bipolar Disord 2000; 2: 336-339

15 Goa KL, Ross SR, Chrisp P. Lamotrigine. A review of its pharmacological properties and clinical efficacy in epilepsy. Drugs 1993; 46: 152-176

16 Greiner C, Wittmann M, Haen E. Lamotrigine serum concentrations under valproate comedication: "contraindication" or "safe combination"? A case report. Pharmacopsychiatry 2007; 40: 287-289 
Notice:

Because of the erratum this contribution has been downloaded again on December $1^{\text {st }}, 2015$

\section{Erratum:}

There was a misunderstanding in our article. In the discussion (page 213, second paragraph, lines 6-7) we stated that "Kagawa et al. even suggested a lamotrigine concentration above $12,700 \mathrm{ng} / \mathrm{mL}$. But the unit in their article is $\mu \mathrm{moL} / \mathrm{L}$. $12.7 \mu \mathrm{moL} / \mathrm{L}$ is equal to $12,700 \mathrm{nmol} / \mathrm{L}$ which is equal to $3252 \mathrm{ng} / \mathrm{ml}$. This supports our findings that lower lamotrigine serum concentrations lead to a therapeutic effect. 